\title{
Tidal modulation of ice shelf buttressing stresses
}

\author{
Alexander A. ROBEL, ${ }^{1,2}$ Victor C. TSAI, ${ }^{1}$ Brent MINCHEW, ${ }^{3}$ Mark SIMONS ${ }^{1}$ \\ ${ }^{1}$ Division of Geological and Planetary Sciences, California Institute of Technology, Pasadena, CA, USA. \\ E-mail: robel@caltech.edu \\ ${ }^{2}$ Department of the Geophysical Sciences, University of Chicago, Chicago, IL, USA \\ ${ }^{3}$ British Antarctic Survey, University of Cambridge, Cambridge, UK
}

\begin{abstract}
Ocean tides influence the flow of marine-terminating glaciers. Observations indicate that the large fortnightly variations in ice flow at Rutford Ice Stream in West Antarctica originate in the floating ice shelf. We show that nonlinear variations in ice shelf buttressing driven by tides can produce such fortnightly variations in ice flow. These nonlinearities in the tidal modulation of buttressing stresses can be caused by asymmetries in the contact stress from migration of the grounding line and bathymetric pinning points beneath the ice shelf. Using a simple viscoelastic model, we demonstrate that a combination of buttressing and hydrostatic stress variations can explain a diverse range of tidal variations in ice shelf flow, including the period, phase and amplitude of flow variations observed at Rutford and Bindschadler Ice Streams.
\end{abstract}

Keywords: Antarctic glaciology, ice dynamics, ice/ocean interactions, ice-sheet modelling, ice shelves

\section{INTRODUCTION}

Ocean tides cause variations in observed glacier flow in Antarctica, Greenland and other glaciated regions (e.g. Walters, 1989; Harrison and others, 1993; Reeh and others, 2000; Podrasky and others, 2014). These flow variations have different amplitudes, periods and phases at different glaciers, indicating that there are multiple physical mechanisms through which tides influence ice-sheet flow. At Whillans Ice Stream, almost all flow occurs through tidally-modulated stick-slip events over basal 'sticky spots' (Bindschadler and others, 2003; Wiens and others, 2008; Lipovsky and Dunham, 2017). At Bindschadler Ice Stream (hereafter BIS), ice flow primarily varies at the same period as the dominant local ocean tides and may be detected over $100 \mathrm{~km}$ upstream of the grounding line (Anandakrishnan and Alley, 1997; Anandakrishnan and others, 2003). At Rutford Ice Stream (hereafter RIS), fortnightly ocean tides (known as $M_{\mathrm{f}}$ and $M_{\mathrm{sf}}$ tides) are weak compared with the dominant high-frequency diurnal and semidiurnal tides. Ice flow velocities in RIS, however, vary almost entirely at the $M_{\text {sf }}$ period (14.77 days), which corresponds to the beat frequency of the two primary semidiurnal tidal constituents. These $M_{\mathrm{sf}}$ velocity variations in RIS are nearly $25 \%$ of the time-averaged flow rate within the ice shelf, and can be detected more than $100 \mathrm{~km}$ upstream of the grounding line (Gudmundsson, 2006; Murray and others, 2007; Brunt and others, 2010; King and others, 2011; Rosier and others, 2015; Minchew and others, 2017).

Many previous studies have suggested that tides can cause flow variations in an ice shelf through changes in hydrostatic and flexural stresses (e.g. Anandakrishnan and Alley, 1997; Gudmundsson, 2007; Goldberg and others, 2014; Thompson and others, 2014; Rosier and Gudmundsson, 2016). Variations in basal stress from tidal currents and variations in driving stress due to changing ice shelf surface slope (Makinson and others, 2012) have also been put forward as potential tidal mechanisms for producing ice shelf flow variability, but have had limited success in reproducing observations in model investigations (Brunt and MacAyeal, 2014).
Once the tidal signal enters the grounded ice stream, models suggest that nonlinearity in the basal sliding law is capable of producing flow variations at periods longer than the tidal forcing in the grounded ice stream, which then propagate up and downstream (Gudmundsson, 2007, 2011; Williams and others, 2012; Rosier and others, 2014; Walker and others, 2014). Yet further studies have suggested that ocean tides lead to variations in ice shelf flow through a decrease in contact with sub-shelf pinning points and sidewalls (Schmeltz and others, 2001; Doake and others, 2002; Heinert and Riedel, 2007; Thomas, 2007; Minchew and others, 2017). However, the extent to which such tidally-modulated changes in ice shelf buttressing combine with other potential tidal forcing mechanisms to produce the period, amplitude and phase of observed changes in ice shelf flow has not been tested in a systematic fashion.

Notwithstanding such modeling advances, the full range of mechanisms that cause ice flow to vary with tides, and their interaction with each other, is still unknown. As GPS stations are deployed for longer durations, more glaciers and ice shelves are being found to exhibit low-frequency variations in ice flow (Rosier and others, 2015). Existing models have proposed explanations for some characteristics of tidal ice flow variations on some glaciers, but not others. Spatially-resolved observations are also calling into question existing theories of low-frequency ice flow variations. For example, new observations from interferometric synthetic aperture radar (InSAR) (Minchew and others, 2017) show that the low-frequency tidal signal in ice flow at RIS originates in the ice shelf, rather than in the grounded ice stream. These observations also indicate that tidal variations in ice shelf strain rate are not uniform, but exhibit significant small-scale variability, suggesting that ice flow variability originates with processes within the ice shelf, rather than being passively advected downstream from the grounded ice stream. Here, we propose explanations for the period, amplitude and phase of tidal signals in ice shelf and ice stream flow. We start by using observations to argue that tides modulate the contact stresses near the grounding line 
and between the ice shelf and sub-shelf bathymetric pinning points. Using a lumped Maxwell model, we show that nonlinearities in ice shelf buttressing with respect to tidal height are the most plausible explanations of low-frequency variations in ice shelf flow. We also find that the phase of high-frequency variations in displacement relative to tidal height indicates whether variations in buttressing or hydrostatic stresses are more important for the modulation of ice flow.

\section{OBSERVATIONAL CONSTRAINTS AND MODEL MOTIVATION}

Observations indicate that a rising ocean tide causes grounding line retreat and lifts the ice shelf away from sub-shelf bathymetric pinning points, decreasing resistance to the flow of the ice shelf (Schmeltz and others, 2001; Doake and others, 2002; Minchew and others, 2017). Conversely, a rising tide also increases hydrostatic stresses in the ice shelf, which increases the resistance to ice flow (e.g. Anandakrishnan and Alley, 1997; Gudmundsson, 2007; Rosier and Gudmundsson, 2016). In this section, we analyze observations of tidally-modulated ice shelf flow variations at two West Antarctic ice streams and discuss which physical processes might play a role in causing these variations.

At RIS, horizontal ice shelf displacement (blue line in Fig. 1a) varies primarily at fortnightly periods, with smaller semidiurnal variations in displacement that are nearly in phase with tidal height (calculated to be $15^{\circ}$ phase lag, though not necessarily discernible in Fig. 1a). At BIS (Fig. 1b), horizontal ice displacement varies at fortnightly and diurnal periods with nearly equal amplitude, with diurnal variations completely out of phase with tidal height $\left(210^{\circ}\right.$ phase lag). At both ice streams, there is a significant low-frequency signal in horizontal displacement downstream of the grounding line. However, the variations in displacement occurring at high tidal frequencies have different

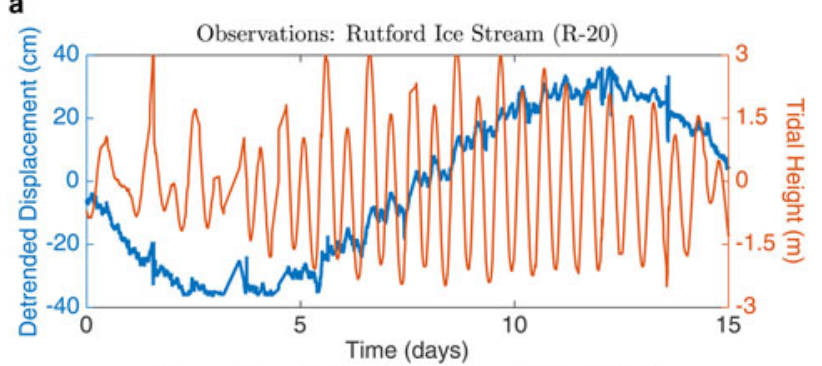

c
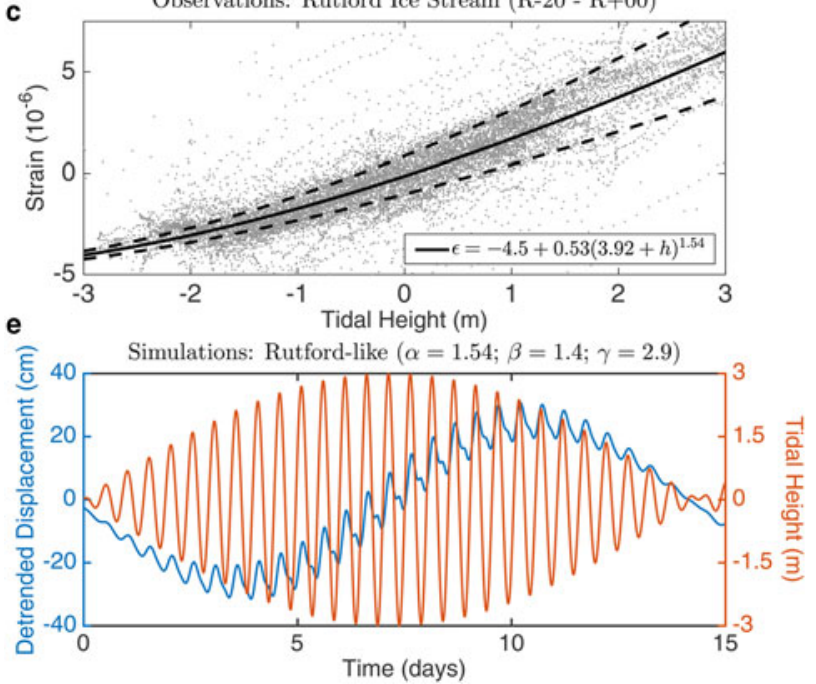

b

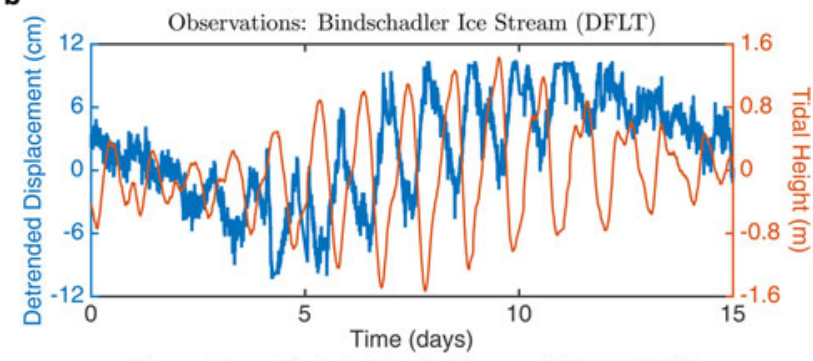

d
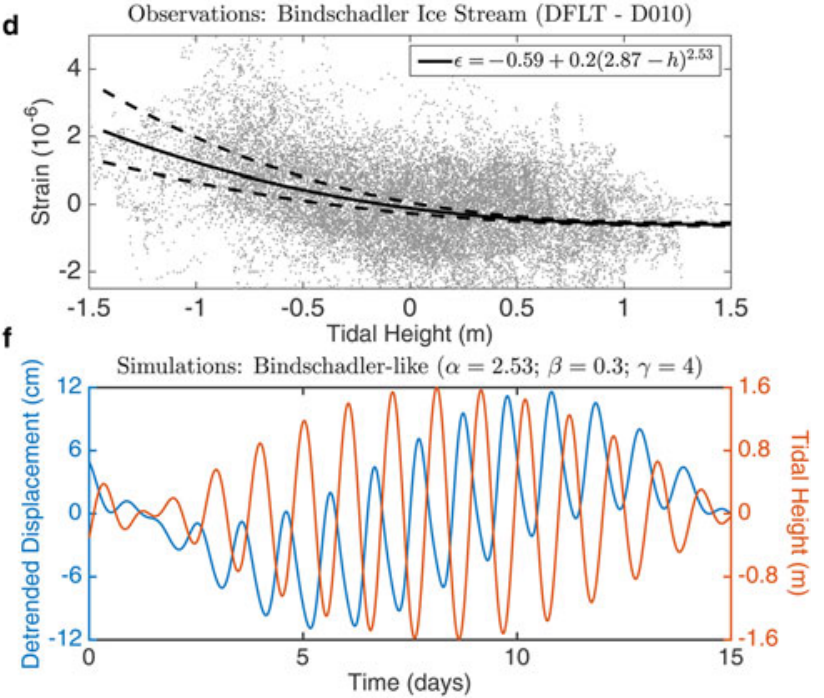

Fig. 1. Observations and model simulations of the tidal response to forcing near and downstream from the grounding lines of two ice streams. (a) Blue line is detrended horizontal along-flow displacement measured at a GPS station downstream of RIS grounding line over one springneap cycle (R-20 in Gudmundsson, 2006, coordinates in Table 1). Red line is detrended vertical displacement measured at this same station. Data from Gudmundsson (2006). (b) Same as (a), but for GPS station downstream of BIS grounding line (DFLT station in Brunt and others, 2010, coordinates in Table 1). Data from personal communication with R. Bindschadler and K. Brunt. (c) Relationship between strain (y-axis) and tidal height (x-axis) just downstream of the RIS grounding line. Grey dots indicate GPS observations. Strain is calculated between the R-20 station, which is $20 \mathrm{~km}$ downstream of the grounding line of RIS and the R+ 00 station, which is on the time-averaged RIS grounding line (as named in Gudmundsson, 2006). Tidal height is measured at the R-20 station on the ice shelf. Solid black line indicates the least squares estimate, written in functional form in the inset box. Dashed black lines indicate the two standard deviation estimates for least-squares parameters (with exponent $\alpha=1.54 \pm 0.06$ ). Measurements of detrended displacement more than two standard deviations different from the mean are removed, followed by smoothing with a 30-minute Gaussian filter. (d) Same as (c), but for strain calculated between the DFLT station, $15 \mathrm{~km}$ downstream of the BIS grounding line, and the D010 station, $\sim 10 \mathrm{~km}$ upstream of the timeaveraged BIS grounding line (as named in Brunt and others, 2010, with exponent $\alpha=2.53 \pm 0.19$ ). Greater measurement error at RIS causes the larger spread in intercept of least squares estimates. (e) Simulated ice shelf flow in a simple viscoelastic model (Eqns (4)-(10)) for a Rutford-like parameter set. Blue line is detrended horizontal displacement and red line is tidal height, as in panels (a, b). In the model, strain is calculated and then integrated over a horizontal length scale corresponding to the distance between GPS stations on an ice stream, $20 \mathrm{~km}$ in the case of RIS and $25 \mathrm{~km}$ in the case of BIS. (f) Same as in (e), but for a Bindschadler-like parameter set. 
phase with respect to tidal height. We aim to explain the causes of these similarities and differences between the tidally-induced ice shelf flow variations at these two ice streams.

We first discuss different ways in which tides cause variations in the stress applied on an ice shelf. To do so, we analyze observations of the relationship between horizontal strain and tidal height at RIS and BIS (Figs. 1c and d, respectively). Strain is measured over a baseline distance between stations near and downstream of the grounding lines of RIS and BIS (with the understanding that ice stream grounding line locations vary with tidal height and measurements of grounding line position are subject to significant errors, see Rignot and others, 2011). Observations are indicated by grey circles, and the least squares fit of the relationship between tidal height and ice shelf strain is indicated by the black solid line (black dashed lines indicate the $\pm 2 \sigma$ least squares fits), with the functional form written explicitly in the inset boxes. For elastic deformations, strain is proportional to the imposed stress. If viscous deformation is small compared with elastic deformation, then the phase of highfrequency variations in observed strain with respect to tidal height are expected to be close to either $0^{\circ}$ or $180^{\circ}$ (see the section 'Parameter exploration of tidal influence on ice shelf flow', below). In such a scenario, measured variations in strain can be used as indicators of variations in stress. In the floating portion of RIS (Fig. 1c), strain is positively correlated (close to $0^{\circ}$ in phase) and nonlinear with respect to tidal height. This nonlinearity indicates that strain is more sensitive to changing tides at high tide than at low tide. In contrast, strain in the floating portion of BIS (Fig. 1d) is negatively correlated (close to $180^{\circ}$ out of phase) and nonlinear with respect to tidal height, with higher sensitivity to changing tides at low tide.

Variations in hydrostatic (and flexural) stresses within an ice shelf are linearly proportional to local tidal height (Holdsworth, 1969; Anandakrishnan and Alley, 1997; Gudmundsson, 2007; Rosier and Gudmundsson, 2016). Thus, our primary goal in this study is to determine mechanisms which can plausibly produce the observed nonlinear relationships between ice shelf strain and tidal height in the ice shelves at RIS and BIS. Spatially-resolved InSAR observations indicate that these tidal strain variations are localized in nature (Minchew and others, 2017), suggesting that the mechanism causing ice shelf flow variations is unrelated to large-scale processes including either changes in ice shelf slopes and driving stresses (Makinson and others, 2012) or changes in the velocity of the grounded ice stream, which advect downstream to the ice shelf (Gudmundsson, 2011). We argue that beyond hydrostatic, flexural and driving stresses, the only way for tides to cause localized variations in ice shelf strain is through variations in resistance from localized contact at the lower and lateral ice shelf surfaces. The total of the stresses exerted back on the grounded ice stream by all different contact points on these pinned ice shelf surfaces is typically referred to as the 'buttressing stress' (Goldberg and others, 2009).

We consider the locations of 'final contact points' where ice goes afloat and loses contact with the bed because the weight of ice is approximately equal (or exactly equal in the hydrostatic limit) to the hydrostatic pressure of ocean water. These final contact points occur at (what is conventionally called) the grounding line, and also at pinning points within the ice shelf where local maxima in bathymetry

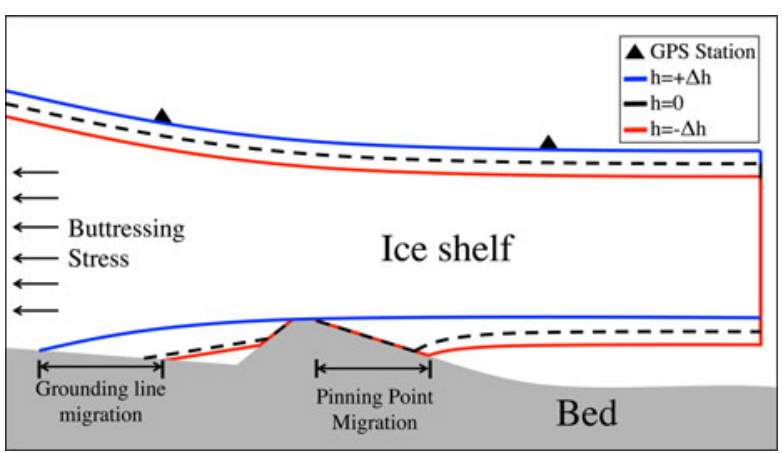

Fig. 2. Explanatory schematic for the mechanisms of tidal modulation of ice shelf buttressing stresses. Tides modulate the location of ice contact with the bed, which occurs at the grounding line and sub-shelf pinning points. The migration of the grounding line and pinning point locations is asymmetric with respect to tidal height (Tsai and Gudmundsson, 2015). Colored lines are positions of ice shelf at different location in the tidal cycle: red is low tide, black dashed is mean tide and blue is high tide. Black triangles correspond to two GPS stations, which would record the change in ice shelf horizontal strain with changing tidal height.

come into contact with the lower ice shelf surface (see schematic example in Fig. 2). Tidal variations in hydrostatic pressure lead to migration of these final contact points and change the total area where ice-bed contact occurs (as previously argued by Anandakrishnan and Alley, 1997). By simply considering where hydrostatic equilibrium occurs near the grounding line and in ice shelves, it has been shown (Tsai and Gudmundsson, 2015) that final contact points (either a grounding line or pinning point) migrate $\sim 10$ times further upstream from mean to high tide than from low to mean tide. This asymmetry arises because spatial variations in ice thickness are set by slow viscous deformation of the ice sheet. However, on the typical timescale of tidal hydrostatic pressure variations $(12-24 \mathrm{~h})$, viscous deformation is too slow to adjust ice thickness in the vicinity of the final contact points in response to the accumulation of hydrostatic stresses.

An explanatory schematic (Fig. 2) shows the asymmetric migration of the grounding line and a pinning point from low to mean to high tide. The precise functional dependence of the total contact area on tidal height will depend on the particulars of local bathymetry. However, if there is nonzero basal shear stress that is approximately spatially uniform over all locations of ice contact, the decrease in the spatially-integrated basal shear stress associated with grounding line retreat will be greater in going from mean to high tide than from low to mean tide. The consequence of

Table 1. Locations of GPS stations (at beginning of observation period of data used in this study) referenced in text and used to calculate ice shelf flow in Fig. 1

\begin{tabular}{ll} 
Station name & Coordinate location \\
\hline R-20 & $78.65^{\circ} \mathrm{S}, 82.67^{\circ} \mathrm{W}$ \\
$\mathrm{R}+00$ & $78.49^{\circ} \mathrm{S}, 83.09^{\circ} \mathrm{W}$ \\
DFLT & $80.50^{\circ} \mathrm{S}, 151.03^{\circ} \mathrm{W}$ \\
D010 & $80.59^{\circ} \mathrm{S}, 148.50^{\circ} \mathrm{W}$
\end{tabular}

Data from Gudmundsson (2006) and personal communication from R. Bindschadler and K. Brunt. 
this asymmetry is a nonlinear relationship between tidal height and the total buttressing stress within the ice shelf. Indeed, at at both RIS and BIS, ice shelf strain is a nonlinear function of tidal height (Figs. 1c and d). To capture this asymmetry, we formulate (in the next section) a very general empirical parameterization for total ice shelf buttressing stress as an increasing function of tidal height with arbitrary shape. We then use observations of the relationship between tidal height and ice shelf strain (e.g. Figs. 1c and d) to constrain the shape of this function, and explore the consequences of this nonlinearity on the observed ice shelf strain using a lumped viscoelastic ice shelf model.

\section{VISCOELASTIC ICE SHELF MODEL}

To determine the relative importance of variations in hydrostatic and buttressing stresses in generating the period, phase and amplitude of observed ice shelf flow variability, we use a lumped viscoelastic model. For simplicity, the normalized tidal height is assumed to be composed of two high-frequency components of equal amplitude

$$
\hat{h}(t)=\frac{1}{2}\left(\sin \omega_{h 1} t+\sin \omega_{h 2} t\right)
$$

By only forcing the model at high frequencies, we can isolate the effect of nonlinearities in the ice shelf dynamics in producing a low-frequency ice shelf response. Also, in reality, highfrequency tidal constituents may have different amplitudes. Regardless, simulations forced directly by tidal heights observed in ice shelves of interest (e.g. red lines in Figs.1a and 1b) do not produce a qualitatively different ice flow response than simulations forced by the simpler tidal height in Eqn (1).

Considering the ice shelf as a simple elastic beam, tidal variations in water level will cause stress variations within the ice shelf through hydrostatic pressure and ice flexure. Changes in hydrostatic stresses within the ice shelf are proportional to tidal height

$$
\Delta \sigma_{x x}=-\rho_{\mathrm{w}} g \Delta h \hat{h},
$$

where $\Delta h$ is the tidal range, $\rho_{\mathrm{w}}$ is the density of ocean water, $g$ is the acceleration due to gravity and negative values denote horizontal compression of the ice shelf (Rosier and others, 2014). Changes in longitudinal stress associated with ice shelf flexure at the lower ice surface around a non-migrating grounding line are proportional to tidal height

$$
\Delta \sigma_{x x}(z=0) \propto-\Delta h \hat{h} e^{-L_{x} x}\left(\cos L_{x} x-\sin L_{x} x\right),
$$

where $L_{x}^{-1}$ is a flexure length scale dependent on ice shelf rheology (Holdsworth, 1969). However, flexural stresses quickly drop off within the ice shelf (Rosier and Gudmundsson, 2016), and average to zero when integrated over the ice shelf thickness. Since we consider such a depth-integrated, lumped representation of an ice shelf in this study, flexural stresses are negligible and thus we only consider hydrostatic stresses,

$$
\sigma_{h}=-\sigma_{h 0} \hat{h}
$$

where $\sigma_{h 0}$ is the magnitude of tidal variations in hydrostatic stress within the ice shelf, which cause compression of the ice shelf at high tide and extension of the ice shelf at low tide.
Downstream of the grounding lines of RIS and BIS, measured ice shelf strain varies nonlinearly with tidal height (Fig. 1), likely as a consequence of tidal asymmetries in grounding line migration and the contact between the ice shelf and sub-shelf bathymetry (as discussed in the section 'Observational constraints and model motivation'). Thus, we can use the shape of the measured relationship between ice shelf strain and tidal height, captured by the (black line) nonlinear least squares estimates in Figs. 1c and $d$, as an empirical measure of the shape of this asymmetry. The equivalent buttressing stress (which as we argue above, is proportional to strain for elastic deformations) is parameterized as an increasing function with arbitrary shape

$$
\sigma_{b}=\beta \sigma_{h 0}\left[2^{1-\alpha}(1+\hat{h})^{\alpha}-1\right]
$$

where $\alpha$ is a shape parameter indicating the strength of the asymmetry in buttressing stress with respect to tidal height (the same shape parameter that is fit in Figs. 1c and d), and

$$
\beta=\frac{\sigma_{b 0}}{\sigma_{h 0}}
$$

is a non-dimensional parameter measuring the relative importance of the magnitude of changes in buttressing stress $\left(\sigma_{b 0}\right)$ to the magnitude of changes in hydrostatic stress $\left(\sigma_{h 0}\right)$. The value of $\beta$ cannot be determined strictly from the strain/height relationship in Figs. 1c and d, since measured strains include the effect of hydrostatic stress variations. The bracketed term in Eqn (5) varies between -1 to 1 regardless of the value chosen for $\alpha$. It should be noted that this parameterized buttressing equation could just as easily have taken other forms, such as a polynomial. Here, we choose this particular functional form of Eqn (5) in order to easily parameterize the magnitude $(\beta)$ and shape $(\alpha)$ of buttressing stress variations with a minimum of parameters and without introducing other potential sources of nonlinearity or asymmetry with respect to tidal height. It is not necessarily the case that the buttressing relationship will be nonlinear (as this form permits the possibility that $\alpha=1$ ), but rather, we use the observations of nonlinearities in ice shelf strain as a guide for setting the value of $\alpha$. In the section 'Parameter exploration of tidal influence on ice shelf flow', we further explore the sensitivity of the modeled ice flow response to the values of $\alpha$ and $\beta$.

We simulate the tidal variations in local ice shelf deformation using a lumped Maxwell model (Tsai and others, 2008) for a viscoelastic beam unconfined in the $y$ and $z$ direction and driven by tidal variations in stress in the $x$ direction

$$
\varepsilon_{x x}=\frac{1}{E}\left(\sigma_{\mathrm{b}}+\sigma_{\mathrm{h}}\right)+\int_{0}^{t} \frac{1}{3 \eta_{\mathrm{e}}}\left(\sigma_{\mathrm{b}}+\sigma_{\mathrm{h}}\right) \mathrm{d} t,
$$

where $\varepsilon_{x x}$ is the longitudinal strain, $E$ is the Young's modulus of ice and $\eta_{\mathrm{e}}$ is the effective viscosity within the ice shelf (MacAyeal and others, 2015). The model is 'lumped' in that it is forced by the average stresses in a section of the ice stream that includes the grounding line and some part of the ice shelf. The effective viscosity in this section of the ice stream is a function of the time-averaged (indicated by overbar) second invariant of the deviatoric stress tensor

$$
\bar{I}_{2}=\frac{1}{2}\left(\bar{\sigma}_{x x}^{2}+\bar{\sigma}_{y y}^{2}+\bar{\sigma}_{z z}^{2}\right)+\bar{\sigma}_{x y}^{2}+\bar{\sigma}_{x z}^{2}+\bar{\sigma}_{y z}^{2},
$$


where we expect that the longitudinal and lateral shear stresses will dominate for ice shelves (as in Goldberg and others, 2014). We separate tidally-driven variations in hydrostatic $\left(\sigma_{\mathrm{h}}\right)$ and buttressing stresses $\left(\sigma_{\mathrm{b}}\right)$ from the sum of the squares of the time-averaged deviatoric stresses $\left(\bar{I}_{2},\right)$ giving an effective viscosity

$$
\begin{aligned}
\eta_{\mathrm{e}} & =\frac{1}{2} A^{-1}\left[\frac{1}{2} \sigma_{\mathrm{b}}(t)^{2}+\frac{1}{2} \sigma_{\mathrm{h}}(t)^{2}+\bar{I}_{2}\right]^{\frac{1-n}{2}} \\
& =\frac{1}{2} A^{-1} \sigma_{h 0}^{1-n}\left[\frac{\beta^{2}}{2}\left[2^{1-\alpha}(\hat{h}+1)^{\alpha}-1\right]^{2}+\frac{\hat{h}^{2}}{2}+\gamma^{2}\right]^{\frac{1-n}{2}},
\end{aligned}
$$

where $A$ and $n$ are the rate factor and exponent in the Nye-Glen constitutive law (Cuffey and Paterson, 2010), respectively, and

$$
\gamma^{2}=\frac{\bar{l}_{2}}{\sigma_{h 0}^{2}}
$$

is a non-dimensional parameter measuring the relative importance of the magnitude of total time-averaged stresses in the ice shelf (such as driving and lateral shear stresses, which determine the time-averaged ice flow) to the magnitude of tidal variations in hydrostatic stress. The driving and other background stresses within the ice shelf are only included in the effective viscosity and nowhere else in the Maxwell model, as we intend to simulate the tidal anomalies in ice shelf deformation, but not the time-averaged ice flow. We choose to separate tidally-varying from timeaveraged terms in the effective viscosity in order to simplify the effective viscosity terms, but this choice has no significant quantitative effect on the results discussed hereafter. The parameterizations and the lumped nature of this viscoelastic model enable straightforward parameter exploration, but would be made unnecessary by a fully 3-D viscoelastic ice-stream model with realistic sub-shelf bathymetry. However, the bathymetry and many other parameters that would be required for such a model are generally poorly constrained. We therefore leave such a modeling approach to future studies (Table 2).

\section{MODELED TIDAL ICE FLOW VARIATIONS AT RUTFORD AND BINDSCHADLER ICE STREAMS}

The lumped Maxwell model we have described can explain why glaciers respond differently to tides. In this section, we focus on the two cases of RIS and BIS where the phase,

Table 2. Parameters used in lumped Maxwell ice shelf model (as described in the section 'Viscoelastic ice shelf model') unless otherwise indicated in text

\begin{tabular}{lll}
\hline Parameter & Description & Value \\
\hline$\sigma_{h 0}$ & Magnitude hydrostatic stress (Pa) & $4 \times 10^{4}$ \\
$E$ & Young's modulus (Pa) & $9 \times 10^{9}$ \\
$N$ & Flow law exponent & 3 \\
$\bar{A}$ & Flow law rate factor $\left(\mathrm{Pa}^{-3} \mathrm{~s}^{-1}\right)$ & $7 \times 10^{-25}$ \\
\hline
\end{tabular}

amplitude and period of tidally-driven ice flow variations are considerably different. We use the lumped Maxwell model to calculate the detrended displacement calculated for parameter regimes similar to these two cases. We have plotted the results in Figs. 1e and f for easy comparison with observations (Figs. 1a and b).

In a Rutford-like case (Fig. 1e, with $\alpha=1.54, \beta=1.4$ and $\gamma=2.9$ ), the ice shelf is forced by tidal variation at $M_{2}$ and $S_{2}$ periods, with hydrostatic stress variations of $55 \mathrm{kPa}$ amplitude (consistent with combined $M_{2}$ and $S_{2}$ tidal height variations of $\sim 6 \mathrm{~m})$. In this case, $\beta>1$ and $\gamma$ is large, corresponding to a situation where changes in hydrostatic stresses are smaller than changes in both buttressing stresses and background stresses in the ice shelf. Variations in simulated displacement are nearly in phase with semidiurnal variations in tidal height. These semidiurnal variations in displacement are smaller in amplitude than the dominant low-frequency signal at the $M_{\mathrm{sf}}$ tidal period, which arises from the buttressing nonlinearity (as $\alpha>1$ in this case). We can understand this low-frequency ice-stream response by noting that a nonlinear power of the tidal height as it appears in Eqn (5) can be expanded as

$$
\begin{gathered}
(1+\hat{h})^{\alpha}=1+\alpha \hat{h}+\frac{\alpha(\alpha-1)}{2} \hat{h}^{2}+\ldots \\
=1+\frac{\alpha}{2}\left[\sin \left(\omega_{h 1} t\right)+\sin \left(\omega_{h 2} t\right)\right]+\frac{\alpha(\alpha-1)}{8}\left[\sin ^{2}\left(\omega_{h 1} t\right)\right. \\
\left.+\sin ^{2}\left(\omega_{h 2} t\right)+2 \sin \left(\omega_{h 1} t\right) \sin \left(\omega_{h 2} t\right)\right]+\ldots,
\end{gathered}
$$

which can be rewritten using the double angle and product to sum of sinusoidal functions

$$
\begin{aligned}
(1+\hat{h})^{\alpha}= & 1+\frac{\alpha}{2}\left[\sin \left(\omega_{h 1} t\right)+\sin \left(\omega_{h 2} t\right)\right]+\frac{\alpha(\alpha-1)}{8} \\
& \times\left[1-\frac{1}{2} \cos \left(2 \omega_{h 1} t\right)-\frac{1}{2} \cos \left(2 \omega_{h 2} t\right)\right. \\
& \left.+\cos \left(\left(\omega_{h 1}-\omega_{h 2}\right) t\right)-\cos \left(\left(\omega_{h 1}+\omega_{h 2}\right) t\right)\right]+\ldots
\end{aligned}
$$

which includes power at a low beat frequency $\omega_{L}=\omega_{h 1}-\omega_{h 2}$. The 'frequency mixing' of Eqn (13) is a mathematical property of any system with nonlinearities, which is forced at more than one frequency. In this case, the nonlinearity arises through processes occurring in the ice shelf. By providing a nonlinear mechanism that produces a low-frequency ice flow response in the ice shelf, we can explain InSAR observations that show that the low-frequency signal at RIS originates in the ice shelf (Minchew and others, 2017). More broadly, with these parameters, the model quantitatively reproduces the characteristic phase, amplitude and frequency of observed flow variations in the ice shelf downstream of RIS (Fig. 1a).

In a Bindschadler-like case (Fig. 1f, with $\alpha=2.53, \beta=0.3$ and $\gamma=4)$, the ice shelf is forced by tidal variation at $O_{1}$ $(25.92 \mathrm{~h})$ and $K_{1}(24.00 \mathrm{~h})$ periods, with hydrostatic stress variations of $30 \mathrm{kPa}$ amplitude (consistent with combined $O_{1}$ and $K_{1}$ tidal height variations of $\sim 3.2$ meters). In this case, $\beta<1$ and $\gamma$ is large, indicating a scenario where changes in hydrostatic stresses are large compared with changes in buttressing stresses and small compared with 
background stresses in the ice shelf. Consequently, diurnal variations in horizontal displacement are close to $180^{\circ}$ out of phase with the prescribed diurnal variations in tidal height. Although the dominant variations in hydrostatic stress are linear with tidal height, nonlinear changes in buttressing stresses ( $\alpha>1$ also in this case) and effective viscosity are sufficiently important to introduce a significant lowfrequency component into the tidal response that is comparable with the amplitude of the diurnal response. This case quantitatively reproduces the phase, amplitude and frequency of ice flow variations at BIS, which are close to $180^{\circ}$ out of phase with tidal height and comparable in amplitude with the low-frequency response (Fig. 1b).

Comparison of the two cases of RIS and BIS shows that even though the dominant tidal periods in the Weddell and Ross Seas are quite different, the existence of an asymmetry in buttressing stresses with respect to tidal height produces an ice stream response that includes variation on long spring-neap timescales for both ice streams. However, there are also important differences in the flow response of BIS and RIS. In particular, there are significant differences in the phasing of the high-frequency ice shelf flow response relative to the dominant tidal forcing and the amplitude of the high-frequency ice shelf flow response relative to the low-frequency flow response.

\section{PARAMETER EXPLORATION OF TIDAL INFLUENCE ON ICE SHELF FLOW}

In this section, we systematically explore the parameter space of the lumped Maxwell model. We explore how the high-frequency phase and dominant period of the modeled variations in ice shelf displacement are functions of parameters $\alpha, \beta$ and $\gamma$. We show that it is the relative importance of tidal variations in hydrostatic and buttressing stresses ( $\beta$ in Eqn (5)), and to a lesser extent the strength of the viscous ice shelf response to tides ( $\gamma$ in Eqn (9)), that cause differences in the tidally-driven ice flow variation at different ice streams. We start by analyzing the phase of high-frequency variations in horizontal ice displacement with respect to tidal height, as a function of $\beta$ and $\gamma$ (Figs. 3a and b) for two values of $\alpha$ that are similar to those for RIS and BIS (see Figs. 1c and d). When $\beta<1$, changes in hydrostatic stresses dominate changes in buttressing stresses and displacement is close to $180^{\circ}$ out of phase with tidal height. Conversely, when $\beta>1$, changes in buttressing stresses dominate and the displacement is nearly in phase with tidal height. There is a sharp transition between these two regimes at $\beta=1$, suggesting that the observed phase lag between high-frequency variations in ice displacement and tidal height (and whether it is near $0^{\circ}$ or $180^{\circ}$ ) is a strong indicator of whether hydrostatic stress variations or buttressing stress variations dominate the tidal modulation of ice shelf flow. Furthermore, increasing $\gamma$ decreases the effective viscosity, therefore increasing the amplitude of the viscous deformation response to forcing, leading to an increase in the phase lag of horizontal displacement with respect to tidal forcing.

To determine the dominant timescale of the ice shelf response to tides, we examine (Figs. $3 c$ and d) the difference between the logarithm of power spectral density $(S)$ for detrended horizontal ice displacement at low frequencies $\left(M_{\mathrm{sf}}\right)$ and the high frequencies of tidal forcing $\left(M_{2}\right.$ and $S_{2}$ in Fig. 3), as a function of $\beta$ and $\gamma$ for the same two values of $\alpha$ as in Figs. 3a and b. Where values are large, the low-frequency response of ice flow to tidal forcing dominates over the high-frequency ice flow response (at the same frequency as the forcing). Changes in $\gamma$ cause two opposite effects in the ice flow response to tidal forcing. When $\gamma$ increases, the time-
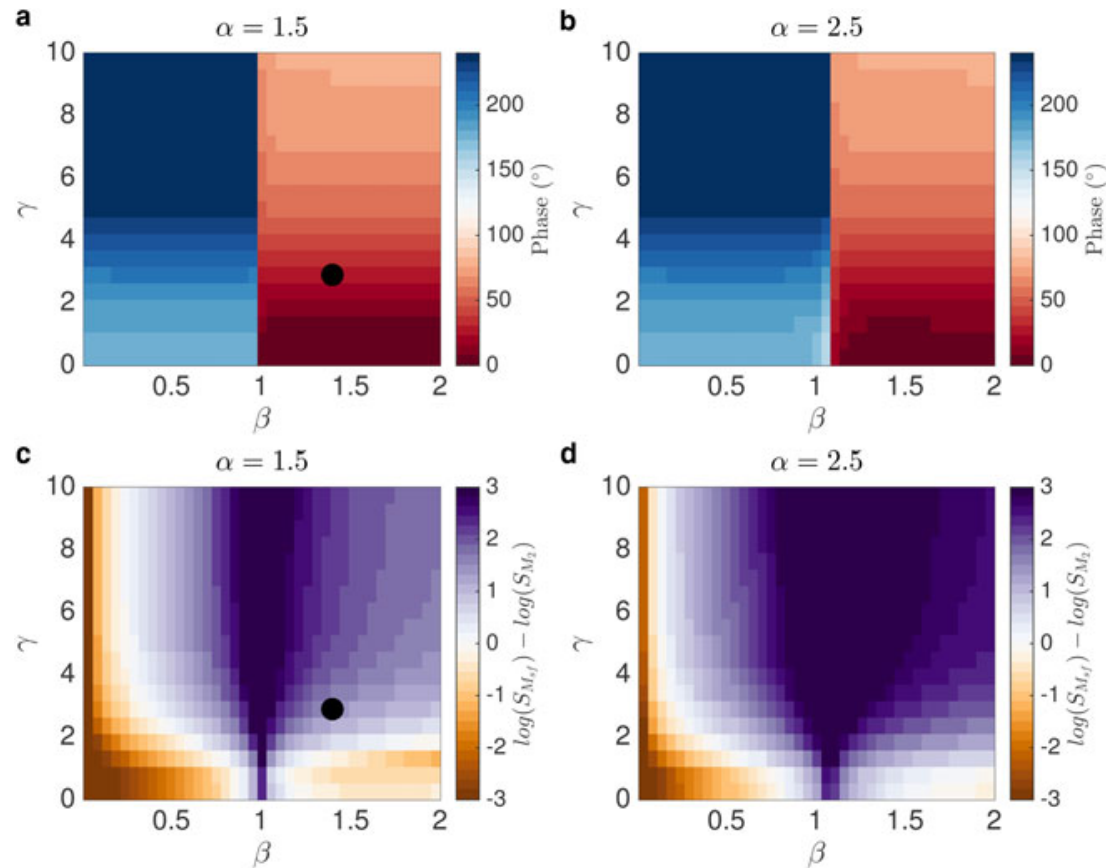

Fig. 3. Parameter space exploration of the response of ice shelf displacement to tidal forcing in the viscoelastic ice shelf model. All panels include variations in $\beta$, the ratio of changes in buttressing stress to hydrostatic stress, on the $x$-axis and $\gamma$, the ratio of time-averaged background stresses in the ice shelf to variations in hydrostatic stress, on the $y$-axis. Black circles indicate parameter set associated with Rutford-like simulation plotted in Fig. 1e. (a, b) Phase lag of $M_{2}$ component of detrended ice shelf displacement with respect to tidal height. (c, d) Difference between the log of power spectral density $(S)$ of detrended horizontal ice displacement at low frequencies $\left(M_{\mathrm{sf}}\right)$ and high frequencies $\left(M_{2}\right)$ of tidal forcing. White shading indicates equal power at low and high frequencies. 
averaged deviatoric stresses in the nonlinear effective viscosity $\bar{I}_{2}$ in Eqn (9)) become larger relative to the tidally-varying terms $\left(\sigma_{\mathrm{h}}\right.$ and $\left.\sigma_{\mathrm{b}}\right)$. The result is that tidal forcing causes proportionately less change in effective viscosity and the nonlinearity of effective viscosity in the Nye-Glen flow law for ice becomes less important. In addition, increasing $\gamma$ decreases the overall magnitude of effective viscosity (through the dependence of viscosity on deviatoric stresses in ice, see Eqn (9)). When the ice shelf strain varies on periods longer than the Maxwell time (the characteristic relaxation timescale for a Maxwell material: $\tau_{\mathrm{m}}=\eta_{\mathrm{e}} / E$ ), the corresponding deformation will primarily be viscous. At lower viscosity, the amplitude of the resulting variations in viscous deformation will be larger, while the high-frequency elastic deformations are largely unchanged (Lakes, 1998). Consequently, this second effect leads to an increase in the amplitude of low-frequency variations in ice flow relative to high-frequency variations with increasing $\gamma$. Figs. 3c and $d$ show that in a range of parameters relevant to ice shelves, increasing $\gamma$ generally leads to an increase in the amplitude of low-frequency components relative to high-frequency components. Thus, we conclude that the second effect is generally more important than the first, except when $\alpha$ and $\gamma$ are low and $\beta$ is very high (like in the bottom right corner of Fig. 3c). We also find that, even when the magnitude of linear changes in hydrostatic stresses dominate nonlinear changes in buttressing stresses $(\beta<1)$, low-frequency variations in ice flow can be significant (as long as $\gamma$ is sufficiently large). Even in the Bindschadler-like case shown in Fig. 1f, there is a significant component of the variation in ice shelf flow occurring at $M_{\text {sf }}$ periods.

As argued in the section 'Modeled tidal ice flow variations at Rutford and Bindschadler ice streams', when $\alpha \neq 1$, the nonlinearity in buttressing stress with respect to tidal height causes mixing of high-frequency forcings to produce a lowfrequency response in ice flow. Thus, increasing $\alpha$ leads to an expansion in the range of parameter space over which the low-frequency ice-shelf response dominates (in Fig. 3, white regions demarcate where this ratio is near one). In the marginal case where variations in buttressing stresses are exactly linear with respect to tidal height $(\alpha=1$; not shown), we find that no amount of viscous nonlinearity is able to produce power at low frequencies. This lack of low-frequency response is similar to previous studies (Gudmundsson, 2007, 2011), which found that the nonlinearity of the Nye-Glen flow law is insufficient on its own to reproduce the low-frequency response of RIS to high-frequency tidal forcing. Other nonlinearities, which come from asymmetries in buttressing in our model (and sliding relations for grounded ice in other studies) are necessary, though not strictly sufficient, to produce a dominantly lowfrequency response in horizontal ice displacement. Given that $\gamma$ is large in most ice streams, we expect there generally to be some detectable ice flow variation at the tidal beat frequency if tides cause variations in ice shelf buttressing stress with magnitude greater than $\sim 25 \%$ of the magnitude of hydrostatic stress variations (with the specific number depending on precise values of $\gamma$ and $\alpha$ ).

\section{DISCUSSION}

A combination of tidal variations in hydrostatic and buttressing stresses can simultaneously explain the phase of high-frequency variations in ice-shelf flow, the origin of low-frequency variations in the ice shelf, and the likely cause of small-scale spatial variability in strain rate in the ice shelf. Other studies have proposed alternative mechanisms through which tides influence ice flow, including variations in ice shelf driving stress, basal friction from sub-shelf tidal currents, subglacial water pressure and nonlinear sliding laws. However, each of these mechanisms has difficulty in explaining particular aspects of existing observations. In one modeling study of the Ross Ice Shelf, Brunt and MacAyeal (2014) were unable to reproduce observed changes in flow through tidally-driven changes in ice shelf driving stress and sub-shelf ocean currents. In other modeling studies of RIS (Gudmundsson, 2007, 2011; Rosier and others, 2014; Thompson and others, 2014; Rosier and Gudmundsson, 2016), tidal modulation of ice flow through variations in subglacial water pressure or nonlinearity in the basal sliding law create a low-frequency signal first in the grounded ice stream, which is then passively propagated uniformly through the ice shelf. Such an $M_{\text {sf }}$ signal in the grounded ice stream would precede (in time) the $M_{\mathrm{sf}}$ signal in the floating ice shelf and also cause uniform changes in ice shelf strain rates. However, Minchew and others (2017) have shown, using spatially-resolved InSAR observations from RIS, that the largest amplitude and earliest appearance of the low-frequency tidal signal in horizontal flow occurs in the ice shelf, not in the grounded ice stream. That same study showed that, in the ice shelf, strain rates do not vary uniformly in space over the $M_{\text {sf }}$ tidal cycle, but rather exhibit significant spatiotemporal variability, presumably due to spatial variations in contact with sub-shelf pinning points. Both InSAR and GPS observations, together with the viscoelastic model of this study, show that processes within the ice shelf are capable of producing variations in ice flow at the spring-neap beat frequency.

The tidal height variations in the sub-shelf ocean cavities of the Ross and Weddell Seas are not spatially uniform (Robertson and others, 1998; Padman and others, 2003). Additionally, other tidal constituents, such as the $M_{\mathrm{f}}$ tide (13.66 days), also cause vertical deflection and horizontal flow variations in the Ross and Filchner-Ronne ice shelves. Further yet, there may also be far-field tidal variations at other ice streams, which cause interactions between the tidal responses of ice streams within an ice shelf. However, these other tidal constituents and interactions seem to be present at much lower amplitudes than the primary semidiurnal and diurnal tides (Padman and others, 2003; Murray and others, 2007) and do not play a significant role in producing the largest amplitude tidal ice flow variations. To account for many of these detailed (but secondary) aspects of observations, future studies may include the processes highlighted in this study in conjunction with fully $3-\mathrm{D}$ viscoelastic ice stream/shelf models with realistic tidal and bathymetric boundary conditions. However, such an approach is beyond the scope of this study.

\section{CONCLUSIONS}

We have shown that asymmetries in buttressing stress with respect to tidal height can produce low-frequency ice flow variations and, in combination with tidal variations in hydrostatic stresses, can also explain the phase of high-frequency ice flow variations. While previous studies have suggested a potential role for tidal variations in buttressing stress (Schmeltz and others, 2001; Doake and others, 2002; 
Heinert and Riedel, 2007; Thomas, 2007; Minchew and others, 2017), we describe a simple viscoelastic model that can quantitatively reproduce the observed temporal variations in ice shelf horizontal displacement at different ice streams. We show that nonlinearities in ice flow dynamics with respect to tidal height cause frequency mixing and ice flow variations at low frequencies corresponding to the beat of the primary tidal frequencies. Viscoelasticity then acts to increase the amplitude of low-frequency ice flow variations relative to the amplitude of high-frequency ice flow variations. We show that the $M_{2}$ and $S_{2}$ tides produce an ice flow response primarily at their beat frequency (the $M_{\mathrm{sf}}$ frequency).

A new generation of observations shows that the ice sheet response to ocean tides is more complex than previously thought. We have proposed new mechanisms of tidal influence on ice flow and a simple model to explain the wide range of tidally-modulated ice flow variability exhibited by glaciers, including the characteristics of tidally-driven ice flow variability at Rutford and Bindschadler Ice Streams. Pinning points beneath ice shelves are difficult to observe, especially when they only make ephemeral contact with the ice shelf. However, as the rate of basal ice shelf melting in West Antarctica increases due to warming of the subshelf ocean cavity (Pritchard and others, 2012), these marginal pinning points are likely to be the most immediate locations of decreasing ice shelf buttressing stress. Thus, observations of tidally-modulated ice shelf flow can potentially reveal the previously hidden influence of pinning points on ice stream flow under changes to the lower ice shelf surface. In this fashion, this study lays the theoretical and conceptual groundwork for pushing further in our understanding of the ice sheet response to tides and future climatedriven changes to ice shelves.

\section{ACKNOWLEDGMENTS}

We thank Doug MacAyeal, Kelly Brunt, Hilmar Gudmundsson and Olga Sergienko for helpful conversations during the completion of this work. We also thank Bob Bindschadler and Hilmar Gudmundsson for providing GPS data. Source code and documentation of the models used in this study are available as public repositories on GitHub: https://github.com/aarobel/. AR has been supported by the NOAA Climate \& Global Change and Caltech Stanback postdoctoral fellowships during the completion of this work. BM was supported by a NSF Earth Sciences Postdoctoral Fellowship award EAR-1452587. This work was also supported by NSF grant EAR-1453263.

\section{REFERENCES}

Anandakrishnan S and Alley R (1997) Tidal forcing of basal seismicity of Ice Stream C, West Antarctica, observed far inland. J. Geophys. Res.: Solid Earth, 102(B7), 15183-15196

Anandakrishnan S, Voigt D, Alley R and King M (2003) Ice Stream D flow speed is strongly modulated by the tide beneath the Ross Ice Shelf. Geophys. Res. Lett., 30(7), 1361

Bindschadler RA, King MA, Alley RB, Anandakrishnan S and Padman L (2003) Tidally controlled stick-slip discharge of a West Antarctic ice stream. Science, 301(5636), 1087-1089

Brunt KM and MacAyeal DR (2014) Tidal modulation of ice-shelf flow: a viscous model of the Ross Ice Shelf. J. Glaciol., 60 (221), 500-508
Brunt KM, King MA, Fricker HA and MacAyeal DR (2010) Flow of the Ross Ice Shelf, Antarctica, is modulated by the ocean tide. J. Glaciol., 56(195), 157-161

Cuffey K and Paterson W (2010) The physics of glaciers, 3rd edn. Pergamon, Cambridge, MA, USA.

Doake C and 6 others (2002) Tide-induced lateral movement of Brunt Ice Shelf, Antarctica. Geophys. Res. Lett., 29(8), 1226

Goldberg D, Holland D and Schoof C (2009) Grounding line movement and ice shelf buttressing in marine ice sheets. J. Geophys. Res., 114, F04026

Goldberg D, Schoof C and Sergienko O (2014) Stick-slip motion of an Antarctic Ice Stream: the effects of viscoelasticity. J. Geophys. Res.: Earth Surf., 119(7), 1564-1580

Gudmundsson $\mathrm{GH}$ (2006) Fortnightly variations in the flow velocity of Rutford Ice Stream, West Antarctica. Nature, 444(7122), 1063-1064

Gudmundsson GH (2007) Tides and the flow of Rutford Ice Stream, West Antarctica. J. Geophys. Res.: Earth Surf., 112(F4), F04007

Gudmundsson GH (2011) Ice-stream response to ocean tides and the form of the basal sliding law. Cryosphere, 5(1), 259-270

Harrison W, Echelmeyer K and Engelhardt H (1993) Short-period observations of speed, strain and seismicity on Ice Stream B, Antarctica. J. Glaciol., 39(133), 463-470

Heinert M and Riedel B (2007) Parametric modelling of the geometrical ice-ocean interaction in the Ekstroemisen grounding zone based on short time-series. Geophys. J. Int., 169(2), 407-420

Holdsworth G (1969) Flexure of a floating ice tongue. J. Glaciol., 8, 385-397

King MA, Makinson K and Gudmundsson GH (2011) Nonlinear interaction between ocean tides and the Larsen $\mathrm{C}$ Ice Shelf system. Geophys. Res. Lett., 38(8), L08501

Lakes RS (1998) Viscoelastic solids. CRC press, Boca Raton, FL, USA, vol. 9

Lipovsky BP and Dunham EM (2017) Slow-slip events on the Whillans Ice Plain, Antarctica, described using rate-and-state friction as an ice stream sliding law. J. Geophys. Res.: Earth Surf., 122(4): 973-1003

MacAyeal DR, Sergienko OV and Banwell AF (2015) A model of viscoelastic ice-shelf flexure. J. Glaciol., 61(228), 635-645

Makinson K, King MA, Nicholls KW and Hilmar Gudmundsson G (2012) Diurnal and semidiurnal tide-induced lateral movement of Ronne Ice Shelf, Antarctica. Geophys. Res. Lett., 39(10), L10501

Minchew B, Simons M, Riel B and Milillo P (2017) Tidally induced variations in vertical and horizontal motion on Rutford Ice Stream, West Antarctica, inferred from remotely sensed observations. J. Geophys. Res.: Earth Surf., 121, 167-190 (doi: 10.1002/2016JF003971)

Murray T, Smith A, King M and Weedon G (2007) Ice flow modulated by tides at up to annual periods at Rutford Ice Stream, West Antarctica. Geophys. Res. Lett., 34(18), L18503

Padman L, Erofeeva S and Joughin I (2003) Tides of the Ross Sea and Ross Ice Shelf cavity. Antarct. Sci., 15(01), 31-40

Podrasky D, Truffer M, Lüthi M and Fahnestock M (2014) Quantifying velocity response to ocean tides and calving near the terminus of Jakobshavn Isbræ, Greenland. J. Glaciol., 60 (222), 609-621

Pritchard $\mathrm{H}$ and 5 others (2012) Antarctic ice-sheet loss driven by basal melting of ice shelves. Nature, 484(7395), 502-505

Reeh N, Mayer C, Olesen OB, Christensen EL and Thomsen HH (2000) Tidal movement of Nioghalvfjerdsfjorden Glacier, Northeast Greenland: observations and modelling. Ann. Glaciol., 31(1), 111-117

Rignot E, Mouginot J and Scheuchl B (2011) Antarctic grounding line mapping from differential satellite radar interferometry. Geophys. Res. Lett., 38(L10504)

Robertson R, Padman L and Egbert GD (1998) Tides in the Weddell Sea. In Jacobs, S. S. and R. F.Weiss, eds. Ocean Ice Atmos.: Interactions Antarct. Cont. Margin, Washington, DC, American Geophysical Union, 341-369. (Antarctic Research Series 75.) 
Rosier S, Gudmundsson G and Green J (2014) Insights into ice stream dynamics through modeling their response to tidal forcing. Cryosphere, 8(5), 1763-1775

Rosier SH and Gudmundsson GH (2016) Tidal controls on the flow of ice streams. Geophys. Res. Lett., 43(9), 4433-4440

Rosier SH, Gudmundsson GH and Green JM (2015) Temporal variations in the flow of a large Antarctic ice stream controlled by tidally induced changes in the subglacial water system. Cryosphere, 9(4), 1649-1661

Schmeltz M, Rignot E and MacAyeal DR (2001) Ephemeral grounding as a signal of ice-shelf change. J. Glaciol., 47 (156), 71-77

Thomas RH (2007) Tide-induced perturbations of glacier velocities. Glob. Planet. Change, 59(1), 217-224

Thompson J, Simons M and Tsai VC (2014) Modeling the elastic transmission of tidal stresses to great distances inland in channelized ice streams. Cryosphere, 8(6), 2007-2029
Tsai VC and Gudmundsson GH (2015) An improved model for tidally modulated grounding-line migration. J. Glaciol., 61(226), 216222

Tsai VC, Rice JR and Fahnestock M (2008) Possible mechanisms for glacial earthquakes. J. Geophys. Res.: Earth Surf., 113(F3), F03014

Walker RT, Parizek BR, Alley RB, Brunt KM and Anandakrishnan S (2014) Ice-shelf flexure and tidal forcing of Bindschadler Ice Stream, West Antarctica. Earth Planet. Sci. Lett., 395, 184-193

Walters RA (1989) Small-amplitude, short-period variations in the speed of a tide-water glacier in south-central Alaska, USA. Ann. Glaciol., 12, 187-191

Wiens DA, Anandakrishnan S, Winberry JP and King MA (2008) Simultaneous teleseismic and geodetic observations of the stick-slip motion of an Antarctic ice stream. Nature, 453(7196), 770-774

Williams CR, Hindmarsh RC and Arthern RJ (2012) Frequency response of ice streams. Proc. R. Soc. A, 468(2147), 3285-3310 